\title{
Non-Muscle Myosin IIA (Myh9) is in the Nucleus of S-Phase Entering NT2-D1 Cells
}

\author{
Gabriela Naum-Onganía ${ }^{1, *}$ and Rolando Rivera-Pomar² \\ ${ }^{1}$ UNLP, Regional Center for Genomic Studies, La Plata, Buenos Aires, Argentina \\ ${ }^{2}$ Bio-Research Center, National University of Pergamino, Buenos Aires, Argentina
}

\begin{abstract}
Non-muscle myosin IIA is a cytoplasmic protein that works in concert with F-actin to produce cell movement. The heavy chain of this protein is codified by the MYH9 gene. The presence of motor proteins as myosin or mono and Factin and their role in transcription has recently been observed. Prep1-the transcription factor of HOXB genesconstitutes a dimer with Pbx1, which induces HOXB gene expression. Prep1 has been found purifying with $\beta$-actin and Myh9. HOXB transcription initiates when cells enter in S-phase, during which DNA duplication and transcription occur at the same time. Here, we have shown that Myh9 co-localizes with Prep1 in the nucleus and in the periphery of the nucleolus in S-phase NT2-D1 cells. Furthermore, we have shown that Myh9 purifies with Pbx1 from nuclear extracts of S-phase entering NT2-D1 cells -and not from cytoplasmic extracts. Taking into account these results, we conclude that Myh9 is in the nucleus of the S-phase entering NT2-D1 cells and might have a role in HOXB transcription.
\end{abstract}

Keywords: Myosin9, Hox genes, NT2-D1 cells, S-phase.

\section{INTRODUCTION}

The myosin's family currently comprises at least 16 classes of motor proteins, and actually, it is known that many members of this family play a role(s) in the transport of intracellular organelles and vesicles [1, 2]. Non-muscle myosin II (NMMII) seems to be the only member of the myosin super-family with the ability to form polymeric molecular assemblies in non-muscle cells. The three mammalian NM II isoforms have both overlapping and unique properties. Owing to its position downstream of convergent signaling pathways, NM II is central in the control of cell adhesion, cell migration, and tissue architecture. In conjunction with F-actin on which NM II moves towards the fastergrowing ends of the filaments, the isoform II A (NMMIIA) plays a role in cell shape changes during the cell cycle, division and spreading [2-5]. Furthermore, it is an actin-binding protein that has actin cross-linking and contractile properties and is regulated by the phosphorylation of its light and heavy chains [5]. In this sense, the heavy chain of non-muscle myosin IIA (NMMHIIA) is codified by the MYH9 gene. NMMHIIA (onwards called Myh9) also takes part in the assembly of the actin filaments network, supporting the plasma membrane of eukaryotic cells -the actin cortex [6, 7].

Recently, evidence on the role of motor proteins in the cell nucleus has been found. Myosin I $\beta$, Va and VI appear to be in a complex with the RNA Pol II affecting

*Address correspondence to this author at the Regional Center for Genomic Studies (CREG) National University of La Plata, Boulevard $120 \mathrm{~N}^{\circ} 1459$, La Plata (1900), Buenos Aires, Argentina; Tel: +54 (0221) 423-6332;

E-mail: gnaum@conicet.gov.ar transcription [8, 9]. $\beta$-actin and myosins have been separately implicated in different aspects of gene expression. Several studies have demonstrated the importance of $\beta$-actin, [10-14] myosins [8, 9] or actin polymerization stimulating proteins in the nucleus, i.e. $\mathrm{N}$-WASP and Arp2/3 $[15,16]$. In this organelle, $\mathrm{N}$ WASP and Arp $2 / 3$ bind RNA Pol II and are required for RNA Pol II-dependent transcription [15, 16]. In addition, electron microscopy has revealed acto-myosin complexes in the interphase nuclei [17]. Moreover, nucleolar acto-myosin complexes are functionally coupled to elongate ribosomal RNA transcripts and are physically associated with both RNA Pol I and ribosomal genes [18], suggesting that acto-myosin motors may provide a general mechanism to facilitate elongation of RNA transcripts during transcription of both ribosomal and protein-coding genes $[18,19]$.

Human NT2-D1 clone is a teratocarcinoma cell line used as a model to study the expression of in vitro HOXB gene. Upon retinoic acid (RA) addition, HOXB cluster genes transcribe collinearly [20]. This occurs during the S-phase when the double strand of the DNA is open [21]. In this model, it has been demonstrated that between the 80 to the $100 \%$ of NT2-D1 RA-treated cells enter in S-phase, i.e. the moment when HOXB genes initiate transcription [21, 22]. In line with this, it is known that HOXB expression is activated by the ternary complex constituted by the regulatory factors Prep1, Pbx1 and HoxB1 [23, 24]. These proteins make a trimer crucial for the induction of HOXB2 gene transcription [25, 26]. Moreover, in previous work, we have shown that nuclear actin is essential to regulate the initial activation and collinear expression of HOXB 
genes [13]. In this work, we show that Myh9 is present in the nucleus of S-phase entering NT2-D1 cells (transcribing HOXB genes) and suggest that this motor protein could be involved -as nuclear actin- in the expression of HOXB genes.

\section{RESULTS}

We have investigated the occurrence of Myh9 in the nucleus of the NT2-D1 clone during the S-phase of the cell cycle. For this purpose, we have used the antibody anti-non-muscle myosin heavy chain, isoform IIA (antiNMMHIIA, see methods). Immunochemical experiments were analyzed by confocal microscopy (Figure 1, panels $A$ to $D$, and panels $H$ and $\mathrm{I}$; Figure 2, panels $A, B, E, F$, and G; Supplementary Figure 1, panels $A$ to $F$ and Supplementary Figure 2, panels $A$ to $D)$. Cell morphology of the S-phase entering NT2-D1 cell line was not controlled by any molecular marker, but by choosing grouping cells spreading on large adhesive patches. Figure 1A shows a group of cells with this morphology, labeled with the anti-Prep1 antibody FITCconjugated (green). During the S-phase, Prep1 is present in the nucleus. The spreading morphology of the NT2-D1 cells indicates -with high precision- that the probability of entering in S-phase (i.e. when HOXB genes are transcribing) is about $90 \%$ [22]. To confirm that those cultures were S-phase HOXB transcribing, cells were treated with RA and used both in western blot and RT-PCR. Panel A shows the intense staining of Prep1 in the nucleus, which coincides with the blot of panel $\mathrm{F}$ (NE, $\mathrm{C}$, and RA lanes). Prep1 bands corresponding to nuclear and cytoplasmic extracts (NE and $C E$, respectively), treated and non-treated with RA, are shown in panel $F$ ( $C$ are non-treated, i.e. controls). NT2-D1 HOXB transcribing cells stained in red (Mhy9) and in blue (nuclei) are shown in panels $B$ and $C$, respectively. By means of confocal microscopy, we have observed that Myh9 (red) co-localizes with Prep1 (green) in the nuclear periphery and in the periphery of the nucleolus of S-phase entering NT2-D1 cells. Colocalization is shown in the squares of panels $A$ to $D$ (yellow/orange). Nuclear and cytoplasmic extracts were blotted onto a membrane labeled with PONCEAU (panel E). After that, the membrane was blocked with dry milk $5 \%$ and incubated with the anti-Prep1 $(62 \mathrm{kDa})$, anti-Thoc1 -an mRNA elongation factor of $84 \mathrm{kDa}-$, anti-Meis 4 -a homolog protein of Prep1 (62kDa)-, and anti-Actin $(43 \mathrm{kDa})$ antibodies (panel F). Notice that Thoc1 is present only in nuclear extracts and not in cytoplasmic ones. Although Meis4 and Prep1 share homology between their sequences, Meis 4 does not react with the anti-Prep1 antibody.
The nuclear markers used in this work, namely Prep1, $\mathrm{Pbx} 1$, and Thoc1, are involved in transcription and RNA processing. As Pbx1 co-localizes with Myh9 (not shown), we have suggested that it interacts with Myh9 and hypothesized that Myh9 might have a role in transcription.

We know that the interaction between Myh9 and Pbx1 might be unspecific in the absence of ATP and $\mathrm{Mg}^{++}$by strong binding to $\mathrm{F}$-actin. For this reason, we have analyzed the presence of this interaction in nuclear eluates obtained by tandem affinity purification, which was performed with buffers with at least $5 \mathrm{mM}$ $\mathrm{Mg}^{++}$(TAP technique, see methods). Thus, we have used Prep1-TAP nuclear eluates (NE Prep1-TAP) and the monoclonal antibody anti-non-muscle myosin heavy chain, isoform IIA (i.e. $\alpha$-Myh9). As we expected, Myh9 precipitated with $\mathrm{Pbx} 1$ in NE but not in $\mathrm{CE}$, suggesting that they interact in the nucleus (panel $G$ ). In order to check the specificity of the secondary antibody, we have incubated NT2-D1 cultures with this. As shown in panel $\mathrm{H}$, the black image indicates that this secondary antibody is specific and does not react with cultures. Panel I shows nuclei stained with DAPI.

To support the notion that Myh9 localizes in the nucleus of S-phase entering the NT2-D1 cells, we have compared the pattern of Mhy9 with the pattern of myosin $1 \beta$, which presence has been demonstrated in the nucleus. Fluorescence patterns of myosin $1 \beta$ and Mhy9 in S-phase entering NT2-D1 nuclei are shown in Figure 2: the former is shown in panel $A$ (myosin1 $\beta$ ); the latter, in panel B (myosin 9). In the last panel, myosin (red) is evident in the nucleus (blue) of the $S$ phase entering NT2-D1 cell. A graphic of nuclear myosin $1 \beta$ (myo1 $\beta$ ) localization is shown in panel C. In this graphic, fluorescence was converted to a grayscale where arbitrary units above 20 (20AU) correspond to the inside of the nucleus. Thus, 20AU indicates the nuclear inside level whereas the arbitrary unit zero (OAU) indicates the background level (black), so that the $A U$ corresponding to myo1 $\beta$ inside the nucleus are above 20; and the AU corresponding to DAPI are bellow 20AU to zero (see panels $A$ and $C$ ). In line with this, the graphic of panel $D$ contains a blue circle that represents the nuclear inside and outside of the nucleus. In this graphic, two high peaks of 80 and 120AU, respectively, match with nuclear periphery (notice the "outside" of the nucleus in panels B and D). To highlight the structures of Figure 1B, we have performed a black and white designed (Figure 2 panel $E)$. A black line that goes through the cell of panel $F$ was 

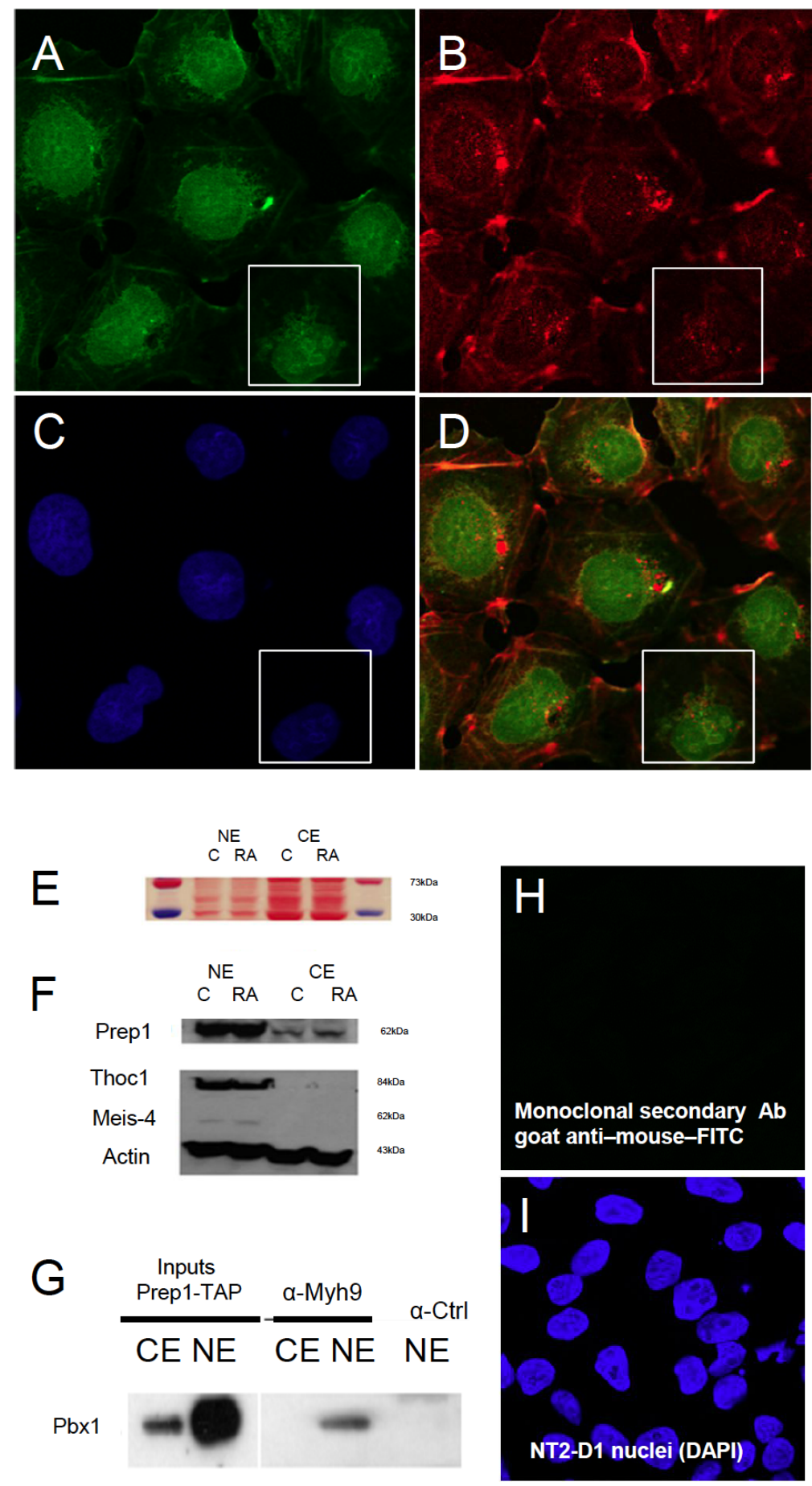

Figure 1: Panel A. S-phase entering NT2-D1 cells stained with the anti-Prep1 antibody FITC-conjugated (green). Panel B. Sphase entering NT2-D1 cells stained with the anti-Mhy9 TRIC-conjugated (red). Panel C. S-phase entering NT2-D1 cells stained with DAPI (blue). Panel D. Prep1 (green) and Mhy9 (red) co-localize in the nucleus and the nucleoli periphery (yellow/orange). Panel E. Western blot membrane stained with PONCEAU of control (C) and retinoic acid (RA) treated NT2-D1 cells showing the protein level in the nucleus and cytoplasm. Nuclear and cytoplasmic extracts are indicated as NE and CE, respectively. Panel F. The membrane of panel E showing nuclear (NE) and cytoplasmic extracts (CE) was blotted against Prep1, Meis4, Thoc1, and Actin. Notice the robust bands of Prep1 in nuclear extracts (treated and non-treated, i.e. RA and C lanes) and the faint bands in cytoplasmic ones. Meis4 was used as a control because it is a Prep homolog protein and Actin was used as housekeeping. Observe nuclear Thoc1 (NE lanes). Panel G. Sequential TAP purification was performed as indicated in Material and Methods. The immuno-precipitation of RA-treated NT2-D1 nuclear extracts was performed with the anti-NMMHIIA antibody (anti-Myh9). Prep1-TAP eluate was immune-precipitated with the a-Myh9 antibody, and then blotted against Pbx1. Lanes (from left to right) correspond to $10 \%$ of Inputs: lysates of cytoplasmic (CE) and nuclear (NE) extracts of NT2-D1 cells (inputs 10\% Prep1-TAP). Prep1-TAP eluate was blotted against Pbx1. Ctrl are control samples blotted against an irrelevant antibody ( $\alpha-\mathrm{Ctrl})$. Notice that as Myh9 is in the nuclear extract (NE), it interacts with Pbx1. Panel H shows a black image corresponding to a culture incubated with the secondary antibody alone, which does not react with the cells. Panel I shows the same cells labeled with DAPI. 

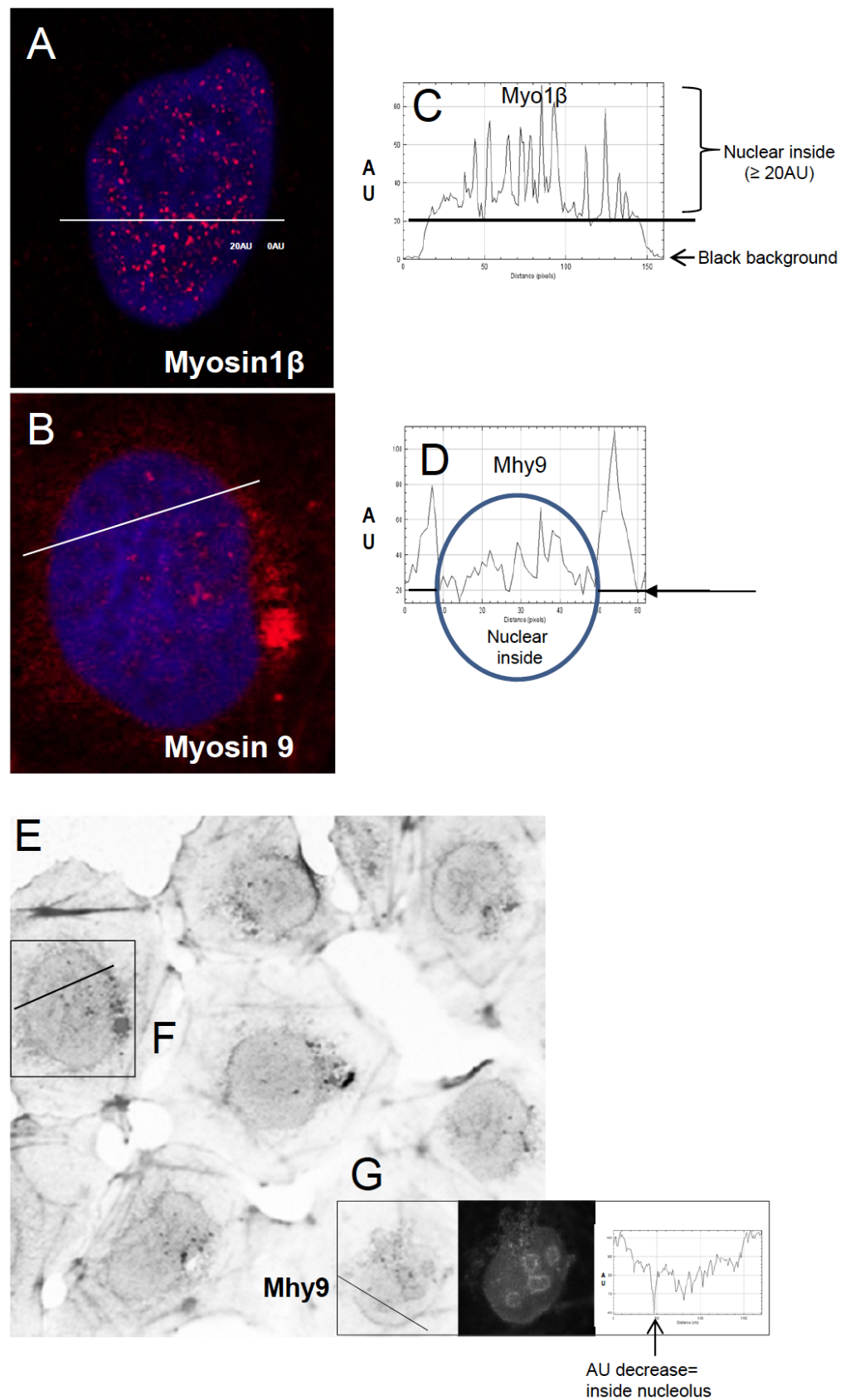

Figure 2: Panel A. Confocal image of nuclear myosin $1 \beta$ in an S-phase NT2-D1 nucleus is shown in red. The nucleus is labeled in blue with DAPI. Confocal images were used to obtain the arbitrary units (AU) of a grayscale (graphics) quantifying the fluorescence intensity of the Myh9 conjugated to a red fluorophore and DAPI (blue). Zero arbitrary units (0AU, black background) of the grayscale indicate the outside of the nucleus, whereas 20AU indicate the inside. Panel B. S-phase NT2-D1 nucleus showing the Mhy9 in red. The nucleus is labeled with DAPI (blue). Panel C. Fluorescence intensity was converted to a grayscale and depicted in the graphic to assay the nuclear myo1 $\beta$ presence. "Nuclear inside level" is indicated by the arbitrary unit 20 $(20 \mathrm{AU})$ whereas the black background corresponds to OAU, so that the AU corresponding to myo1 $\beta$ fluorescence are above of 20 and the $A U$ corresponding to the inside of the nucleus are below of 20. Panel D. Taking into account the red and blue intensities of the confocal image of panel B, graphic shows a blue circle which indicates the nuclear inside and outside. Notice the line corresponding to 20AU (see the arrow at this level), which also indicates the limit between nuclear inside (bellow 20AU) and outside (above 20AU). Nuclear periphery in panel B (red) coincides with the "outside" of the circle in the graphic (panel D). This "outside" matches the two high peaks of 80 and 120AU of the graphic. Panel E. Fluorescence intensity of Figure 1D was converted to a grayscale to highlight the structures by a black and white image. In the cell of panel $F$, a line was used as a reference to perform the graphic of panel D. Panel G. In the cell of panel G, a line was used as a reference to perform the graphic of this panel. In this panel (middle), Myh9 is highlighted in the periphery of the nucleoli where it co-localizes with Prep1 (compares with Figure 1D). So that if the periphery of the nucleolus is inside the nucleus then Mhy9 is inside the nucleus, as well. Notice the decrease of the Myh9 label from 100 to $60 \mathrm{AU}$ (corresponding to the loss of Myh9 fluorescence) which indicates the inside of the nucleolus. As observed, the fall coincides with $60 \mathrm{AU}$ whereas the periphery of the nucleolus corresponds to 85 $\mathrm{AU}$, suggesting that Mhy9 is in the nucleus of the cell. 
used to perform the graphic of panel D. Myh9 is shown in panel $G$ in the periphery of the nucleolus, therefore, if the periphery of the nucleolus is inside the nucleus of the cell, then Mhy9 is inside the nucleus, as well. Notice the decrease of the label of Mhy9 from 100 to $60 \mathrm{AU}$, which corresponds to the loss of Myh9 fluorescence that matches the inside of the nucleolus. In summary, this fall in the $\mathrm{AU}$ of the graphic coincides with the inside of the nucleolus (60AU) whereas the periphery of the nucleolus corresponds to $85 \mathrm{AU}$, suggesting that Mhy9 is inside the nucleus.

Supplementary Figure 1, panels $A$ to $C$, shows a snapshot of an S-phase entering NT2-D1 cell (HOXB transcribing genes) $[22,23]$. The nucleus was stained with DAPI (blue) and the cytoplasm with the anti-Myh9 antibody (red). Compare the bars between panels $B$ and $E$ and notice the big nucleus in panel $B$. Control cells that do not contain Myh9 are shown in panels $D$ to $\mathrm{F}$ (these cells were non-treated with RA and therefore, they were not spreading). To support the fact that NT2D1 spreading cells are HOXB transcribing ("entering in S-phase"), we have performed an RT-PCR from RAtreated NT2-D1 cells. A robust band corresponding to the HoxB2 transcript, which was transcribed upon $48 \mathrm{~h}$ RA-treatment [20] (lane 48, S-phase), is shown in panel G. In order to confirm that Mhy9 is inside the nucleus of NT2-D1 HOXB transcribing cells, we have used another cell line that expresses HOXB genes. Although the hematopoietic K562 cells express the HOXB2 gene, they do not contain Myh9 in the nucleus. This is shown by a black and white image in panel $D$. (Supplementary Figure 2, panels B and D). Nuclei were labeled with the anti-Thoc1 antibody FITC-conjugated (green, panel A) and cells were labeled with the antiMhy9 antibody TRITC-conjugated (red, panel B). In conclusion, and taking into account the evidence presented in this work, we can confirm that Myh9 is inside the nucleus of the S-phase entering NT2-D1 cells.

\section{DISCUSSION}

The dimer Prep1/Pbx1 is required for the activation of the HOXB gene expression [24, 25] Upon RA-10M ${ }^{-5}$ induction, Prep1, Pbx1, the elongating form of the RNA Pol II (phosphorylated at ser2 position of the CT domain or 2Pser) and $\beta$-actin, are recruited on the HOXB2 gene enhancer of the NT2-D1 RA-inducible cells $[13,14]$, as the induction produced by interferon over the ISRE-containing genes [27]. This suggests that actin-containing transcription complex is related with the Prep1 regulatory region during the induction of the HOXB gene transcription process.
It has been shown that Prep1 co-precipitates with $\beta$ actin and with the heavy chain of NMMIIA (Myh9) [28]. A similar result was obtained with the nuclear actin polymerization inducer, N-WASP, and the accessory transcription/splicing factors PSF and p54 $4^{(\mathrm{nrb})}$ [15], both of which interact with N-WASP in the nucleus after RA induction [13, 14]. In previous work, we have shown that nuclear actin aggregates co-localize with the elongating form of RNA pol II in nuclear speckles, where actin polymerizes, so that these speckles contain G-, F-actin and Thoc1 -the mRNA elongation factor which labels nuclear speckles and interacts with the accessory transcription/splicing factor PSF [13]. This last stimulates $3^{\prime}$ end cleavage in the absence of pre-mRNAs splicing and requires the RNA Pol II CT domain for stimulating the pre-mRNA processing [29]. In our previous work, we have shown that the interaction between Thoc1 and PSF has been enhanced by the RA-treatment, as PSF and nuclear actin [13]. In summary, we have hypothesized that nuclear actin is involved in splicing and genome organization in the cellular nucleus.

Here, we have shown that Myh9 -a motor protein that interacts with F-actin- is in the nucleus of the RAtreated NT2-D1 cells, i.e. entering in S-phase. Because it has been shown that Prep1 binds $\beta$-actin and Myh9 [28] and co-localizes with this -and with its nuclear polymeric form upon RA-transcriptional induction [13]-, we hypothesize that nuclear F-actin and Myh9 might be involved in the dynamical transcription process of the HOXB genes.

Many studies of nuclear actin and myosin have suggested that these two proteins associate with each other might either serve a function in transcription complex formation or act as molecular motors that drive transcription [13-19]. In fact, the induction of HOXB gene expression by RA is accompanied by the movement of the cluster outside the chromosomal territory and towards the center of the nucleus. This evidence suggests that the localization of the HOXB genes (inside or outside the chromosomal territory) may be a visual manifestation of chromatin decondensation [30, 31], i.e. the initiation of S-phase. Therefore, nuclear F-actin and Myh9 might provide a structural matrix for transcription. In the simplest case, nuclear actin and Myh9 might just have a structural rather than a catalytic role, anchoring the DNA and the transcription machinery into chromatin or nonchromatin nuclear regions. However, this view of a mere architectural function is not supported by data for in vitro transcription experiments. 
Another model that is tempting to speculate suggests that Myh9 and F-actin work together as molecular motors driving RNA polymerase II for the movement of the DNA during transcription. According to this, Myh9 might bind the Pbx1 transcription factor (that in turn binds Prep1, forming an active dimer) whereas the head of the light chain of myosin IIA could interact with nuclear F-actin, which in turn might bind RNA polymerase II during transcription activation and elongation. Moreover, it is known that $\mathrm{p} 54^{(\mathrm{nrb})}$ bind $\mathrm{N}$ WASP and that N-WASP induces actin polymerization [15]. Thus, if Myh9 "walks" over the actin filament, then, these two proteins may be involved in a directional movement (towards the faster-growing end of the actin filament, as we proposed in our previous work [13]). The hypothetical binding of Myh9 to the Prep1/Pbx1 dimer and of $\beta$-actin to the elongating RNA polymerase II might suppose to generate an ATP-dependent force that powers the sliding of RNA polymerase on the DNA. However, we have not evidence that nuclear actin and Myh9 interact physically because the MYH9 gene codifies for the heavy chain of the non-muscle myosin IIA (NMMHIIA or Myh9). Nevertheless, our point of view is that so probably myosin and actin work together as motor proteins in the same way that is demonstrated for the cytoskeleton. Despite we know that the interaction between actin and NMMIIA is mediated by the light chain, we think that there is no reason to think in a more complex possibility. Thus, it is tempting to speculate that the ATPase activity of nuclear actin and myosin could be used to regulate the transcription complex formation or to promote mRNA elongation.

In summary, we have shown the nuclear presence of Myh9 inside the nucleus of S-phase entering NT2D1 cells. Moreover, we have shown the association of Myh9 with Pbx1 -which moves from the cytoplasm into the nucleus and binds Prep1. Prep1 links to DNA and co-purifies with $\beta$-actin and Myh9, as has been already demonstrated [28]. In summary, we have additional evidence about this novel nuclear motor protein, to help to provide information on how transcription, RNA processing, and nuclear architecture could be interconnected.

\section{MATERIALS AND METHODS}

\section{Cell Cultures}

Human NT2-D1 cells were grown in DMEM (Cambrex BioScience) and used at $70 \%$ confluence. Trans-retinoic acid was from Sigma-Aldrich. Controls were treated with $0.1 \%$ DMSO, the vehicle of RA. NT2D1 cells were treated with RA $1 \mu \mathrm{M}\left(10^{-6} \mathrm{M}\right)$ to obtain an
$80-100 \%$ S-phase cell population [22]. Cell morphology was controlled by choosing grouping cells spreading on large adhesive patches, which indicates that the probability of entering in S-phase (i.e. when HoxB genes are transcribing) is about of $90 \%[22,23]$.

\section{Treatments}

RA $10^{-6} \mathrm{M}(1 \mu \mathrm{M}$ RA) was added to the cells at $0 \mathrm{~h}$ time point for 48 hours (i.e., $48 \mathrm{~h}$ RA-treatment). Control cultures were treated with the vehicle of RA treatment, DMSO. The HoxB2 transcript level was measured by conventional RT-PCR at the end of each RA-treatment (Figure 2, panel G).

\section{Quantitative Reverse Transcription (RT-PCR) and PCRs}

RNA $1 \mu \mathrm{g}$, oligo dT $1 \mu \mathrm{l}(0,5 \mathrm{ng})$ and SuperScript First-Strand Synthesis System for RT-PCR kit (Invitrogen) were used. Primers were as follows: GADPH: ACCACCTGGTGCTCAGTGTA (sense) and ACATCATCCCTGCCTCTACTG and HOXB2: AGT GGA ATT CCT TCT CCA GTT CC (antisense) and TCC TCC TTT CGA GCA AAC CTT CC (sense). cDNA $5 \mathrm{ng}$, was amplified (in triplicate) with the GoTaq polymerase (Promega, Milan, Italy) and measured in the ABI/Prism $7900 \mathrm{HT}$ Sequence Detector System (Applied Biosystems), using a pre-PCR step of $2 \mathrm{~min}$ at $94^{\circ} \mathrm{C}, 50$ cycles of [denaturalization: $30 \mathrm{~s}$ at $94^{\circ} \mathrm{C}$; annealing: $1 \mathrm{~min}$ at $62^{\circ} \mathrm{C}$; elongation $1 \mathrm{~min}$ at $72^{\circ} \mathrm{C}$ ] and finally, a termination of $7 \mathrm{~min}$ at $72^{\circ} \mathrm{C}$. RNA without reverse transcriptase was used as negative control. 18S rRNA and GAPDH were used as standards (not shown). Proprietary primers from TIB MOLBIOL Srl. were used. The amount of HoxB2 mRNA was $1 \mu \mathrm{g}$ for each sample.

\section{Antibodies}

The following antibodies were used: purified mouse anti- $\beta$-actin monoclonal antibody (Sigma Aldrich, C4 clone or Actin), mouse monoclonal anti-Thoc1 (also known as anti-p84 (ab487)) both from Abcam. Covance Anti-NMMIIA (anti-Myh9) heavy chain was used. Monoclonal anti-Prep1 and anti-Pbx1 were from Santa Cruz Biotechnology (Santa Cruz, CA). For Prep1 detection, also polyclonal antibodies were used. Donkey anti-mouse-FITC and donkey anti-mouseTRITC were from Jackson.

\section{Confocal Immunofluorescence}

For immunofluorescence of permeabilized NT2-D1 and K562 cells, monolayers plated on poly-(lysine)- 
coated coverslips were fixed with $4 \%$ paraformaldehyde in PBS at $4^{\circ} \mathrm{C}$ for 10 minutes, washed and quenched with $0.1 \mathrm{M}$ glycine. Primary antibodies against Thoc1, NMMHIIA (Mhy9) and Pbx1 were diluted in $1 \%$ bovine serum albumin (BSA) and $0.1 \%$ Triton and then applied onto coverslips for $1 \mathrm{~h}$ at room temperature. After thorough washing, cells were labeled with secondary antibodies conjugated to fluorophores and with 4',6-diamidino-2-phenylindole (DAPI). All cell samples were analyzed in a confocal TCS SP5 Leica microscope with an oil immersion objective 63x, 1.4 NA (UNLP, La Plata, Argentina). To quantify co-localization and to create the black and with images, the Image $\mathrm{J}$ software was used.

\section{RNA and Protein Extraction, Co-Immunopreci- pitation (Co-IP), Immunoblotting}

RNA was extracted with Trizol (Invitrogen) as the manufacturer indicates. Protein extraction from nuclear extracts was prepared as described by Dignam et al., 1983 [32].

Co-IPs from nuclear and cytoplasmic extracts of NT2-D1 cells was performed from Prep1-TAP eluates (see below). Immunoblots (SDS-PAGE 10\%) were incubated with the antibodies anti-Prep1, anti-Pbx1, anti-Thoc1, anti-Actin, and anti-Meis4.

\section{Tandem Affinity Purification}

TAP technique was performed with the Prep1-TAP vector in two non-denaturing steps: 1) binding to an IgG matrix and elution with the TEV protease 2) purification with calmodulin-coated beads in the presence of calcium. Retrovirus infection: Cells were infected using a retrovirus produced in Phoenix ecotropic packaging cells and selected with puromycin. NE and CE extraction: Cells expressing Prep1-TAP were lysed to obtain nuclear (NE) and cytoplasmic (CE) fractions. Lysates were resuspended in buffer I $(10 \mathrm{mM}$ HEPES KOH pH 7.9, $5 \mathrm{mM} \mathrm{MgCl}_{2}, 10 \mathrm{mM} \mathrm{KCl}, 0.5 \mathrm{mM}$ DTT plus a cocktail of protease inhibitors) and with $1 / 30$ of the volume of $10 \%$ Triton $X-100$. Cell extracts were centrifuged for $1 \mathrm{~min}$ at $11000 \mathrm{rpm}$. The resulting nuclear pellets were treated with buffer III $(20 \mathrm{mM}$ HEPES pH 7.8, 25\% glycerol, $420 \mathrm{mM} \mathrm{NaCl}, 5 \mathrm{mM}$ $\mathrm{MgCl}_{2}, 0.2 \mathrm{mM}$ EDTA plus protease inhibitors) for 30 min at $4^{\circ} \mathrm{C}$ and centrifuged at $13000 \mathrm{rpm}$ during 15 min. Supernatants were nuclear (NE) and cytoplasmic $(\mathrm{CE})$ fractions. The last (CE) was treated with 0.11 volume of buffer II (0.3M HEPES $\mathrm{pH} 7.9,1.4 \mathrm{M} \mathrm{KCl}$, $30 \mathrm{mM} \mathrm{MgCl} 2$ ), rotated for $30 \mathrm{~min}$ at $4^{\circ} \mathrm{C}$ and centrifuged for $15 \mathrm{~min}$ at $13000 \mathrm{rpm}$. IgG binding: Both nuclear and cytoplasmic extracts (NE and $\mathrm{CE}$ ) were adjusted to IgG-binding conditions (IBB buffer: $10 \mathrm{mM}$ Tris- $\mathrm{HCl}$ at $\mathrm{pH} \quad 8,0.2 \% \mathrm{NP}-40,150 \mathrm{mM} \mathrm{NaCl}$ ), incubated in batch with $\operatorname{lgG}$ beads (Amersham Biosciences, Amersham Place, UK) and rotated O.N. at $4^{\circ} \mathrm{C}$. TEV cleavage: After washing with IBB buffer and with TEV cleavage buffer (TCB: $10 \mathrm{mM}$ Tris- $\mathrm{HCl}$ at $\mathrm{pH} 8$, $150 \mathrm{mM} \mathrm{NaCl}, 0.2 \% \mathrm{NP}-40,0.5 \mathrm{mM}$ EDTA, $0.5 \mathrm{mM}$ DTT), TEV cleavage was performed by incubation with

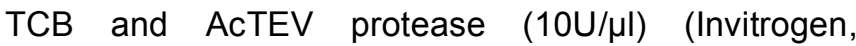
Carlsbad, CA) for $2 \mathrm{~h}$ on a rotator shaker at $16^{\circ} \mathrm{C}$. Calmodulin binding and elution: TEV eluate treated with $\mathrm{CaCl}_{2}$ and $\mathrm{CBB}$ buffer $(50 \mathrm{mM}$ Tris- $\mathrm{HCl} \mathrm{pH} 8$, $150 \mathrm{mM} \mathrm{NaCl}, 1 \mathrm{mM} \mathrm{Mg}$-acetate, $1 \mathrm{mM}$ imidazole, $4 \mathrm{mM}$ $\mathrm{CaCl}_{2}, 0.2 \%$ NP-40, $10 \mathrm{mM} \beta$-mercaptoethanol) was added and mixed with calmodulin beads (Stratagene, La Jolla, CA) at $4^{\circ} \mathrm{C}$. Calmodulin beads were washed with CBB and boiled with 2X Laemmli buffer. Buffers I and III were modified from Dignam et al., 1983.

\section{ACKNOWLEDGEMENT}

This work was supported by CONICET (PIP0247/2011 to GNO), ANPCyT (PICT1528/2008 to GNO and PICT 1237/2008 to RRP) and the Max Planck External Partner Laboratory Program to RRP. GNO and RRP are investigators of CONICET (Argentina).

The authors declare do not have any conflict of interest.

\section{SUPPLEMENTARY FIGURES}

The supplementary figures can be downloaded from the journal website along with the article.

\section{REFERENCES}

[1] Ikonen E, de Almeid JB, Fath KF, Burgess DR, Ashman K Simons K, Stow JL. Myosin II is associated with Golgi membranes: identification of p200 as non muscle myosin II on Golgi-derived vesicles. J Cell Sci 1997; 110: 2155-2164.

[2] Cheney RE, Riley MA, Mooseker MS. Phylogenetic analysis of the myosin superfamily. Cell Motil Cytoskelet 1993; 24: 215-223.

https://doi.org/10.1002/cm.970240402

[3] Sellers JR. Myosins: a diverse superfamilly. Biochim Biophys Acta 1496: 3-22 (2000) Mochida S, Kobayshi H, Matsuda Yuda Y, Muramoto K, Nonomura Y. Myosin II is involved in transmitter release at synapses formed between rat sympathetic neurons in culture. Neuron 1994; 13: 11311142.

[4] Manzanares MV, Ma X, Adelstein R, Rick. Horwitz A. Nonmuscle myosin II takes centre stage in cell adhesion and migration. Nat Rev Mol Cell Biol 2009; 10: 778-790.

https://doi.org/10.1038/nrm2786 
[5] Gloushankova NA, Alieva NA, Krendel MF, Bonder EM; Feder HH, Vasiliev JM, Gelfand IM. Cell-cell contact changes the dynamics of lamellar activity in no transformed epiteliocytes but not in their ras-transformed descendants. PNAs USA 1997; 94: 879-883. https://doi.org/10.1073/pnas.94.3.879

[6] Li D, Miller M, Chantler PD. Association of a cellular myosin II with anionic phospholipids and the neuronal plasma membrane PNAs USA 1994; 91: 853-857. https://doi.org/10.1073/pnas.91.3.853

[7] Pestic-Dragovich L, Stojiljkovic L, Philimonenko AA, Nowak $G$, Hunt DF, Hozak P, de Lanerolle P. A myosin I isoform in the nucleus. Science 2000; 290: 337-341. https://doi.org/10.1126/science.290.5490.337

[8] Vreudge S, Ferrai C, Miluzio A, Hauben E, Marchisio PC, Crippa MP, Bussi M, Biffo S. Nuclear myosin VI enhances RNA polymerase II-dependent transcription. Mol Cell 2006; 23: $749-55$

https://doi.org/10.1016/j.molcel.2006.07.005

[9] Hu P, Wu S, Hernandez N. A role for $\beta$-actin in RNA polymerase III transcription. Genes \& Dev 2004; 18: 30103015. https://doi.org/10.1101/gad.1250804

[10] Kukalev A, Nord Y, Palmberg C, Bergman T, Percipalle P. Actin and hnRNP $U$ cooperate for productive transcription by RNA polymerase II. Nature Struct Mol Biol 2005; 12: 238244

https://doi.org/10.1038/nsmb904

[11] Hofmann WA, et al. Actin is part of pre-initiation complexes and is necessary for transcription by RNA-polymerase II. Nature Cell Biol 2004; 6: 1094-1101. https://doi.org/10.1038/ncb1182

[12] Naum-Ongania G, Diaz VM, Blasi F, Rivera-Pomar R. Nuclear actin polymerization from faster growing ends in the initial activation of Hox gene transcription. Are nuclear speckles involved? Transcription 2013; 4: 260-272. https://doi.org/10.4161/trns.27672

[13] Ferrai C, Naum-Ongania G, Longobardi E, Palazzolo M, Disanza A, Victor M Diaz, et al. Induction of HoxB Transcription by Retinoic Acid Requires Actin Polymerization. MBC 2009; 20: 3543-3551. https://doi.org/10.1091/mbc.e09-02-0114

[14] Wu X, Yoo Y, Okuhama NN, Tucker PW, Liu G, Guan JL. Regulation of RNA-polymerase-II-dependent transcription by $\mathrm{N}$-WASP and its nuclear binding proteins. Nature Cell Biol 2006. On line publication, $10.1038 /$ ncb1433

[15] Yoo Y, Wu X, Guan J. A novel role of the actin- nulceating Arp2/3 complex in the regulation of RNA polymerase IIdependent transcription. J Biol Chem 2007; 282: 7616-7623. https://doi.org/10.1074/ibc.M607596200

[16] Amankwah KS, De Boni U. Ultrastructural localization of filamentous actin within neuronal interphase nuclei in situ. Exp Cell Res 1994; 210: 315-325. https://doi.org/10.1006/excr.1994.1044

[17] Philimonenko VV, et al. Nuclear actin and myosin I are required for RNA polymerase I transcription. Nature Cell Biol 2004; 6: 1165-1172.

https://doi.org/10.1038/ncb1190

[18] Fomproix N, Percipalle P. An actin-myosin complex on actively transcribing genes. Experimental Cell Research 2004; 294: 140-148.

https://doi.org/10.1016/j.yexcr.2003.10.028
[19] Simeone A, Acampora D, Arcioni L, Boncinelli E. Sequential activation of Hox 2 homeobox genes by retinoic acid in human embryonal carcinoma cells. Nature 1990; 346: 763766.

https://doi.org/10.1038/346763a0

[20] Fisher D, Mechali M. Vertebrate HoxB gene expression requires DNA replication. EMBO J 2003; 22: 3737-48. https://doi.org/10.1093/emboj/cdg352

[21] Spinella MJ, Freemantle SJ, Sekula D, Chang JH, Christie AJ, Dmitrovsky E. Retinoic acid promotes ubiquitination and proteolysis of cyclin D1 during induced tumor cell differentiation. J Biol Chem 1999; 274: 22013-8. https://doi.org/10.1074/jbc.274.31.22013

[22] O'Neill C, Jordan P, Ireland G. Evidence for two distinct mechanism of anchorage stimulation in freshly explanted and 3T3 Swiss mouse fibroblasts. Cell 1986; 44: 489-96. https://doi.org/10.1016/0092-8674(86)90470-8

[23] Berthelsen J, Zappavigna V, Mavilio F, Blasi F. Prep1, a novel functional partner of $\mathrm{Pbx}$ proteins. EMBO J 1998; 17 1423-33. https://doi.org/10.1093/emboj/17.5.1423

[24] Berthelsen J, Zappavigna V, Ferretti E, Mavilio F, Blasi F. The novel homeoprotein Prep1 modulates $\mathrm{Pbx}-\mathrm{Hox}$ protein cooperativity. EMBO J 1998; 17: 1434-45. https://doi.org/10.1093/emboj/17.5.1434

[25] Jacobs Y, Schnabel CA, Cleary ML. Trimeric association of Hox and TALE homeodomain proteins mediates Hoxb2 hindbrain enhancer activity. Mol Cell Biol 1999; 19: 51345142. https://doi.org/10.1128/MCB.19.7.5134

[26] Testoni B, Vollenkle C, Guerrieri F, Gerbal-Chaloin S, Blandino G, Levrero M. Chromatin dynamics of gene activation and repression in response to interferon alpha (IFN (alpha)) reveal new roles for phosphorylated and unphosphorylated forms of the transcription STAT2. J Biol Chem 2011; 286: 20217-27. https://doi.org/10.1074/jbc.M111.231068

[27] Diaz VM, Bachi A, Blasi F. Purification of the Prep1 interactome identifies novel pathways regulated by Prep1. Proteomics 2007; 7: 2617-23. https://doi.org/10.1002/pmic.200700197

[28] Rosonina E, Ip JY, Calarco JA, Bakowski MA, Emili A, McCracken S, Tucker P, Ingles CJ, Blencowe BJ. Role for PSF in Mediating Transcriptional Activator-Dependent Stimulation of Pre-mRNA Processing In vivo. Mol Cell Biol 2005; 25: 6734 https://doi.org/10.1128/MCB.25.15.6734-6746.2005

[29] Chambeyron S, Bickmore WA. Chromatin decondensation and nuclear reorganization of the HoxB locus upon induction of transcription. Genes Dev 2004; 18: 1119-1130. https://doi.org/10.1101/gad.292104

[30] Morey C, Kress C, Bickmore WA. Lack of bystander activation shows that localization exterior to chromosome territories is not sufficient to up-regulate gene expression. Genome Res 2009; 19: 1184-94. https://doi.org/10.1101/gr.089045.108

[31] Dignam JD, Martin PL, Shastry BS, Roeder RG. Eukaryotic gene transcription with purified components. Methods Enzimology 1983; 101: 582-98 https://doi.org/10.1016/0076-6879(83)01039-3 